\title{
¿DÓNDE ESTAMOS CUANDO NACEMOS? REFLEXIONES SOBRE DANZA Y NACIMIENTO A PARTIR DE P. QUIGNARD Y G. DELEUZE
}

\author{
Where are we when we are born? \\ Reflections on dance and birth from P. Quignard and G. Deleuze \\ Carlos Casanova Pinochet \\ Universidad Metropolitana de Ciencias de la Educación, Santiago, Chile \\ carloscasanovap@yahoo.com.ar
}

\section{Resumen}

Este ensayo reflexiona sobre el hábito y el habitar del hombre en el momento de su fin, de su finalización, pero que es también el momento de su aparición monstruosa, de su comienzo a un comienzo sin fin y sin telos, no presente, como experiencia que lleva al pensamiento al límite del no-saber ¿Dónde estamos cuando nacemos? ¿Dónde estamos cuando pensamos? Son las dos preguntas que resuenan aquí en torno a la cuestión del habitar en el fin del hombre. En la constelación de pensadores contemporáneos como Michel Foucault, George Bataille y Jean-Luc Nancy, el ensayo explora en la relación entre el concepto de hábito en Gilles Deleuze y la imagen de danza que Pascal Quignard vincula a la e-moción del nacimiento. Si el hábito se refiere en Deleuze a un modo de habitar el mundo mientras que el nacimiento se refiere en Quignard a un no-lugar, entonces la cuestión que se nos plantea es la de la relación entre vida y hábito.

Palabras clave: hábito, habitar, danza, nacimiento, fin del hombre

\begin{abstract}
This essay thinks on the habit and the dwelling of man in the moment of his end, of his completion, but which is also the moment of his monstrous appearance, of his beginning to a beginning without end and without telos, not present, as experience that takes thought to the limit of non-knowledge. Where are we when we are born? Where are we when we think? These are the two questions that resonate here around the question of inhabiting the end of man. In the constellation of contemporary thinkers such as Michel Foucault, George Bataille and Jean-Luc Nancy, the essay explores the relationship between the concept of habit in Gilles Deleuze and the dance image that Pascal Quignard links to the e-motion of birth. If the habit in Deleuze refers to a way of inhabiting the world while the birth in Quignard refers to a non-place, then the question before us is that of the relationship between life and habit.
\end{abstract}

Keywords: habit, dwell, dance, birth, end of man

Fecha de Recepción: 01/07/2019 - Fecha de Aceptación: 26/11/2019 
1.

En 1981 el filósofo francés Gilles Deleuze insistió sobre una cuestión que forma parte esencial de su pensamiento. Cito:

\begin{abstract}
[Existe] una potencia vital que desborda todos los dominios y los atraviesa. Esta potencia es el Ritmo, más profundo que la visión, la audición, etcétera (...). Y el ritmo aparece como música cuando inviste el nivel auditivo, como pintura cuando inviste el nivel visual. (...) Lo último es por tanto la relación del ritmo con la sensación, que pone en cada sensación los niveles y los dominios por los que pasa. Y este ritmo recorre un cuadro de igual modo que recorre una música. Es sístole-diástole: el mundo que me captura cerrándose sobre mí, el yo que se abre al mundo, y lo abre él mismo (2009 49).
\end{abstract}

Si nos quedamos con la última frase de la cita ("el mundo que me captura cerrándose sobre mí, el yo que se abre al mundo, y lo abre él mismo"), podemos observar en ella una similitud con lo que tempranamente, en 1968, Deleuze pensó desde el punto de vista del concepto empirista de "hábito". Un hábito, nos dice en Diferencia y Repetición, es la manera singular en que somos según el modo de habitar que nos constituye. Es decir, un hábito es lo que se contrae por contemplación, una captura o implicación de fuerzas heterogéneas que componen un medio. No sólo el medio en el que vitalmente somos, sino ese medio que, más fundamentalmente, somos. Según el texto de Deleuze, cada uno, cada ser -cada cuerpo y cada órgano-, es una individuación que tiene exactamente la consistencia de sus hábitos. Somos, escribe Deleuze, los miles de hábitos que nos componen. Antes que el yo contemple, el yo es contemplación, un "yo pasivo" que, sin embargo, "no se define tan sólo por la receptividad, es decir, por la capacidad de experimentar sensaciones, sino por la contemplación contrayente que constituye al organismo mismo antes de constituir sus sensaciones" (1988 150). Para Deleuze, en efecto, "hay que atribuir un alma al corazón, a los músculos, a los nervios, a las células, pero un alma contemplativa, cuyo papel es contraer un hábito" (1988 143). Estamos hechos, escribe Deleuze, de todas esas "almas intensivas". En lugar de designar la unidad de una división orgánica de órganos que se definen por una función especializada, el organismo se refiere al cuerpo intensivo de órganos múltiples que se definen por las "síntesis pasivas" o contemplaciones. Un organismo no es más que el compuesto de una infinidad de "factores individuantes", de "síntesis orgánicas" o "sujetos larvarios" que son la suma de contracciones, de retenciones y de esperas. Como cualquier otro órgano del cuerpo, las vísceras tienen alma, en el sentido de que son la envoltura, el mundo como ese pliegue singular de un afuera que constituye al órgano contemplativo. En tal sentido, somos según Deleuze los órganos que habitamos y que nos pueblan. Un hábito es siempre una multiplicidad. Un cuerpo una multitud. Y los órganos, la 
infinidad de almas que nos componen, son la injusticia del mundo, el fondo de desigualdad sobre el que Dios hace al mundo mediante cálculo, pero sin que sus cálculos den nunca en lo justo (1988 357).

No sólo el cuerpo no es lo múltiple que se dice de una totalidad orgánica; tampoco el alma es la unidad atemporal del conjunto de nuestras representaciones. Por tanto, otro concepto (no orgánico de cuerpo) y otro concepto (no sustancial) de alma. En Gilles Deleuze el alma no es lo que se opone al cuerpo: ella es síntesis, es decir, no unidad, sino ligazón y pliegue, simbiosis de heterogéneos que hacen al cuerpo. Cada uno su cuerpo según su alma. Según Deleuze no sentimos el mundo sin antes devenir un mundo como nuestro propio ritmo, la sístole-diástole de nuestra existencia.

Alma, sujeto o yo, no son los términos de una unidad personal o sustancial. En consecuencia, el yo -como bien aclara Anne Sauvagnargues- no posee los caracteres de la subsistencia, de la identidad consigo mismo. "No es algo dado, por lo tanto, ni tampoco la unidad de un resultado, sino el término de una relación en devenir" (Sauvagnargues 24). No hay que olvidar, nos dice Deleuze, el carácter múltiple, móvil y comunicante de la individualidad: su carácter implicado. "El yo no tiene modificaciones, él mismo es una modificación" (1988 150). En vez de ser lo indivisible es "lo que no cesa de dividirse cambiando de naturaleza" (1988 383), precisamente porque es el puro "tener lugar" de una contracción móvil, fluctuante, apersonal, inorgánica. "Hay yo -escribe Deleuze- desde el momento en que se establece en algún lado una contemplación furtiva, desde que en algún lado empieza a funcionar una máquina de contraer, capaz en un momento de sustraer una diferencia a la repetición" (1988 150). El yo es "una diferencia sonsacada", es decir, la diferencia extraída y contraída que habita la repetición. Vale decir, desde el punto de vista de ese otro concepto de cuerpo y de ese otro concepto de alma que están implicados en el concepto empirista-deleuzeano de hábito, el autor de Diferencia y Repetición desarrolla a su vez otro concepto de subjetividad. El sujeto, según Deleuze, es un modo de ser, una manera de habitar el mundo, y como tal, él no es otra cosa que las modalidades de una modificación. En lugar de definirse a partir de las variaciones contingentes de una estructura psíquica invariante, el yo es concebido a partir de los hábitos (las maneras de ser o síntesis espaciotemporales) sobre el plano de una variación continua.

\section{2.}

La frase de 1981 “el mundo que me captura cerrándose sobre mí, el yo que se abre al mundo, y lo abre él mismo", corresponde a lo que en 1968 Deleuze llamó "hábito". Ahora bien, en uno de sus últimos libros, en ¿Qué es la filosofía?, Deleuze escribió: “El hábito es creador. La planta contempla el agua, la tierra, el nitrógeno, 
el carbono, los cloruros y los sulfatos, y los contrae para adquirir su propio concepto, y llenarse de él. El concepto es un hábito adquirido contemplando los elementos de los que se procede". Por tal razón, "no se está en el mundo, se deviene con el mundo, se deviene contemplándolo" (1994 106-107). Nos volvemos con el mundo que nos captura, abriéndonos a él, abriéndolo en un devenir que nos divide, y dividiéndonos, nos modifica. A esta variación intensiva Deleuze la llama también imaginación. "Sustraer a la repetición algo nuevo -escribe Deleuze en Diferencia y Repetición-, sustraerle la diferencia, tal es el papel de la imaginación o del espíritu que contempla en sus estados múltiples y atomizados [...]; la verdadera repetición es la de la imaginación". Bajo el yo que actúa, "somos contemplaciones, somos imaginaciones” (1988 143-145). La imaginación-mundo, el devenir con el mundo como "diferencia sonsacada", como modificación, es la corriente subterránea que atraviesa al sujeto, al yo activo. Un río fluye bajo la acción, bajo el sujeto de la praxis: el flujo de la imaginación que se confunde con su espíritu.

En la línea de lo que plantea Gabriel Tarde, Deleuze sostiene que los hábitos no se tienen; más bien los hábitos son el "tener" que hace nuestro ser. "Se es solo lo que se tiene, solo gracias a un tener se forma el ser, o solo gracias a un tener el yo pasivo es" (1988 150). Pero tener es algo distinto de una propiedad; es, como se puede inferir de lo anterior, un devenir con el mundo. Y este devenir es una forma muy particular de habitar. El tener -escribe Deleuze- es un hábito que se adquiere habitando (1994 107). El hábito es una forma de tener, y este tener es un modo especial del habitar.

Según Deleuze, se habita sin estar en el mundo, sino deviniendo con él; plegándose con el mundo al que nos abrimos como una variación suya.

Dos años antes de la publicación de Diferencia y Repetición, en 1966, se había publicado el libro de Foucault Las palabras y las cosas, donde este -como es sabidoseñala que el hombre moderno es el hombre cuya humanitas ya no es identificable, por tanto es ese hombre cuya figura se confunde con su propia borradura. Con la emergencia del cogito moderno, nos dice Foucault, el "pienso" no conduce más a la evidencia del "soy" (337).

Si la aparición del hombre, según Foucault, se confunde con su desaparición, es porque él se levanta como una consecuencia: la consecuencia de la ausencia de respuesta a la pregunta kantiana “¿Qué es el hombre?”. El hombre, en otras palabras, es el que solo habita en y como la ausencia de respuesta a la propia pregunta, que es la pregunta de lo propio. Su figura es la "aparición gemela" de una imagen que va acompañada de su doble: la sombra o la imagen que falta en la figuración de sí. El hombre surge dividido, en sí doblado, repetido por lo "Otro" que lo distancia de sí, que lo vuelve a sí en la proximidad de una extrañeza tanto más extraña cuanto más íntima es. Esa ausencia de respuesta que es el hombre a la 
pregunta de lo propio es, para Foucault, "la distancia que ahueca lo Mismo, es el rodeo que lo dispersa y lo recoge en los dos extremos de sí mismo" (353).

Me parece que no podemos leer Diferencia $y$ Repetición sino es anteponiéndole la tesis de los últimos capítulos de Las palabras y las cosas. Hacia el final del penúltimo capítulo, Foucault sostiene que "si el descubrimiento del Retorno [nietzscheano] es desde luego el fin de la filosofía, el fin del hombre es el retorno al comienzo de la filosofía. Actualmente solo se puede pensar en el vacío del hombre desaparecido. Pues este vacío no profundiza una carencia; no prescribe una laguna que haya que llenar. No es nada más, ni nada menos, que el despliegue de un espacio en el que por fin es posible pensar de nuevo" (355).

El despliegue de ese espacio en el que por fin es posible pensar de nuevo es para Deleuze el espacio de la repetición y de la diferencia. Es el espacio, según él, del "yo disuelto" como identidad. "Diferencia, distancia, desigualdad, tales son escribe Deleuze en 1968- los caracteres positivos de la profundidad como spatium intensivo" (1988 381). En este espacio de disolución del yo, y que es la escena misma del yo, su aparición (la injusticia del mundo, ha escrito Deleuze), "no es lo mismo lo que retorna, ni lo semejante tampoco, sino que lo Mismo es el retornar de lo que retorna, es decir, de lo Diferente, y lo semejante es el retornar de lo que retorna, es decir, de lo Disímil" (1988 471). El comienzo de un nuevo pensamiento de la diferencia, del eterno retorno nietzscheano como "inversión completa del mundo de la representación y del sentido que 'idéntico' y 'semejante' tenían en ese mundo" (1988 471), coincide así con la aniquilación del hombre que se interna en la línea de fuga del tiempo. Pero esta aniquilación es a su vez, según Deleuze, la aparición misma del hombre sobre la escena. Sobre esta escena (y como la escena misma de la repetición) lo Mismo, para siempre descentrado, gira en torno a la diferencia, como el retornar de lo que vuelve en tanto que disímil. Se trata ahora de un mundo acósmico, sin cielo, como el espacio de una aparición monstruosa; la ausencia de ser en que habita el hombre como la escena de su propia desaparición.

Podríamos decir, en consecuencia, que en Deleuze -lo mismo que en Foucault- el retorno al comienzo de un nuevo pensar equivale al retorno al comienzo de un nuevo habitar del hombre. Sin embargo, se trataría de un habitar paradójico, ya que ahora el hombre habitaría en el espacio de borradura de sí; habitaría en el espacio de ausencia de su humanidad, fuera de sí, en la escena de repetición de lo que retorna desviado, fuera de quicio, como el simulacro de sí mismo: la máscara tras la cual no se esconde rostro alguno, sino solo la aparición monstruosa que está en el fondo de todo reconocimiento, de toda semejanza.

\section{3.}

Desde entonces se impone la pregunta arendtiana: “¿Dónde estamos cuando pensamos?" (Arendt 2010 217-236). Pero si la cuestión del “cogito moderno" es la 
del fin del hombre, de su desaparición; si el pensamiento es lo que comienza en el espacio de retirada del hombre hacia su fin, que es a su vez el espacio de su venida a la presencia como aparición monstruosa, entonces eso quiere decir que la cuestión de dónde estamos cuando pensamos equivale a esta otra: "¿Dónde estamos cuando nacemos?". Saber imposible, imposibilidad del saber expuesto al límite de esta imposibilidad y cuyo máximo exponente es, seguramente, Georges Bataille. Ese pensador que tanto fascinaba a Foucault y no tanto a Deleuze. Este saber de lo imposible, que es también imposibilidad del saber, su paso al límite, no solo es saber de la muerte sino también saber del nacimiento, del surgimiento del hombre, o del hombre como surgimiento, como estallido del "Ser". Mejor dicho: como el "Ser" en tanto que estallido. Bataille escribe en uno de sus ensayos: "Ser en un sentido fuerte [...] es precisamente desencadenarse" (60-66). Leyendo a Bataille, entre otros, Nancy (1996) comenta: exención de sí, el hombre pasa infinitamente al hombre, no es sino este paso; la venida y la sorpresa de ser, su surgimiento, es el origen sustraído a toda lógica de origen, a toda arqueología, es la an-arquía de un brotar singular, del que el ser en cuanto ser no es ni el fondo, ni el elemento, ni la razón, sino la libertad; libertad de ser (libertad que libera al ser y libera del ser): el puro estallido de un existe.

A este surgimiento que es a su vez "desasimiento del ser", enteramente expuesto a su libre venida, y que liberado a sí y de sí está enteramente abandonado a la libertad de existir (Nancy 103-105), Pascal Quignard, otro próximo de Bataille, lo llama en uno de sus libros "danza" o nacimiento.

\section{4.}

Bajo el yo que actúa, "somos contemplaciones, somos imaginaciones". En el fondo del sujeto de la acción y de la voluntad, dice Deleuze, somos los miles de yo larvarios que nos habitan y que son los hábitos de los que procedemos. En consecuencia, si tenemos un cuerpo no es porque este sea una propiedad del yo, sino porque somos la infinidad de hábitos que se adquieren habitando el cuerpo. Habitar, en el sentido de un devenir, es una manera tan intensa de tener las costumbres o los hábitos que ya no es posible poseerlos, porque los somos. Entonces nos volvemos ese Ritmo en el que desaparecemos: la sístole y la diástole de la existencia como repetición, como el estado de la diferencia infinitamente redoblada, infinitamente repetida y llena de resonancias (Deleuze 1988 358).

Ahora bien, ese Ritmo -esa Danza como dice P. Quignard- no puede sino ser nocturna. Nocturna es, según este, la escena del yo, lo no visible que se sustrae a la mirada. Quignard (2005), sin embargo, en lugar de pensar dicha escena como la corriente que fluye bajo el "yo activo", la piensa como lo "Anterior" que se 
diferencia de todo pasado. Podríamos decir que aquí Quignard está, en cierto modo, más cerca de Georges Bataille que de Gilles Deleuze. Y lo está porque introduce un elemento que es más bien ajeno al pensamiento de este, a saber: el elemento de la pérdida, del despojo, del arrebato. Lo anterior, lo "nocturno antesolar", más antiguo que la luz, se refiere en Pascal Quignard a la pérdida originaria, pérdida anterior a cualquier objeto perdido. La escena nocturna es la imagen que nos falta, la noche de sexos divididos que copulan sin nuestra presencia porque de esa danza provenimos antes de nuestro nombre y antes de que fuésemos yo; es asimismo la cópula, la división que nos concibió; y la bolsa intramaterna que durante nueve meses nos envolvió a ciegas como el medio no objetivo; y la vulva que fue nuestra vía, pero también la puerta de salida de una vida que nace y que al nacer se despide, se suelta del cuerpo perdido para siempre. “Una pérdida sin objeto, así es el nacimiento" (2017 109).

Si la cuestión del fin del hombre, de su desaparición, no es sino la cuestión misma de su nacimiento, de su aparición o venida a la presencia, pero de una venida o llegada que es también la partida en el movimiento de retirada de la presencia humana, de lo humano como presencia; y si esta aparición paradojal del hombre es el retorno al comienzo de un nuevo pensamiento, entonces cabe preguntar: ¿no es acaso este pensamiento uno que piensa desde la pérdida y que está expuesto a la finitud radical en relación a esta pérdida originaria? ¿Qué significa comenzar desde el punto de vista del nacimiento en tanto que pérdida y partida? Si es verdad lo que dice Quignard, que el nacimiento es pérdida sin objeto, entonces eso quiere decir que el nacimiento no puede ser objeto del pensamiento. El nacimiento es lo que no se deja representar, y en tal sentido, es el límite de un pensar sin objeto, expuesto él mismo al estallido de un comenzar sin fin y sin origen.

"¿Qué significa el hecho de haber nacido?", “¿Dónde estamos cuando pensamos?", son dos cuestiones inseparables, e incluso intercambiables, que Arendt nos ha legado, pero cuyas respuestas fueron muy insuficientes. Autores posteriores como Nancy o Quignard, ambos próximos a la cuestión del "fin del hombre", han aportado elementos centrales para abordar dichas preguntas. Si Arendt concibe el nacimiento como un intento de redimirnos del final y salvar de alguna manera la presencia ante la posibilidad de una destrucción que se ha vuelto inminente (Arendt 2007 640; Arendt 2005 200-230), estos autores, en cambio, lo piensan como el lugar mismo de la desaparición, de la retirada de la presencia. En el caso de Deleuze, se trata de un pensamiento que está esencialmente vuelto al fondo de lo impensado del cual él emerge. Ese impensado que, para Pascal Quignard, es la imagen que nos falta de nuestra propia imagen. La sombra o el doble nocturno que acompaña y acosa a lo visible (2014; 2005). 
5.

La imagen que hoy nos falta es, según Quignard, la escena de toda escena, la danza que nos precede. Nuestro nacimiento y lo que es anterior al nacimiento. Danza de cuerpos que se cortejan, se acercan para estar juntos, que van y vienen sin orden previo, que se empeñan en las vueltas y revueltas. Se rozan, se frotan, se desean. Cuerpos que copulan y se desatan en un viaje que los aniquila en una pequeña muerte que repite la caída inicial de esos cuerpos cuando han nacido. Pequeña muerte de la que a su vez procedemos como la anterioridad nocturna que vela nuestro comienzo, nuestra salida al exterior atmosférico, pulmonar.

En uno de sus libros, Georges Didi-Huberman escribe que "ninguna antropología, ningún proyecto que considere la condición humana desde la perspectiva de eso que llamamos, sin duda pretenciosamente, 'ciencia del hombre' puede siquiera emprenderse sin plantear la cuestión crucial de la danza" (13). Podríamos decir que Quignard lleva esta tarea al punto límite de su intensidad. Pero a fuerza de ampliar el concepto de danza y extenderlo a la e-moción del nacimiento, a la expulsión del cuerpo neonato de la esfera intrauterina; al estremecimiento del vientre que precede a la salida y al desgarro materno, al pataleo del infante que anuncia su partida; y al movimiento desfalleciente de los cuerpos que se abrazan y son envueltos por la noche en la que los rostros se desfiguran y la decencia se pierde.

Hay, dice Quignard, una "indigencia originaria", que a su vez puede ser definida como la e-moción del nacimiento. La emoción de la creación (2017 108). Esta indigencia tiene que ver, como hemos visto, con la pérdida sin objeto. Quignard escribe: "Perder a la madre que se ignoraba hasta entonces como propia no es una pérdida que pueda ser definida como tal -el que pierde se ignora allí"(2017 108). Todo comienzo, toda creación, toda obra "aparece" a-partir del dolor de la separación natal, como el acto de una indigencia que renueva, es decir repite, una pérdida más fuerte que cualquier objeto que se pierda. "Toda obra renueva una pérdida más fuerte que lo que ella aporta al mundo"(2017 108). Vale decir, toda obra es el resto catastrófico de una partida que la precede y que se repite con ella.

Por consiguiente, que el fin del hombre, su retirada, sea el retorno al comienzo del pensamiento, de un pensamiento que comienza a pensar en el vacío del hombre, en la escena de aparición de un yo que desaparece, no puede, según lo dicho anteriormente, significar un simple tránsito de una filosofía a otra, de una vieja forma de pensar a otra nueva. En ningún caso quiere decir una refundación de la filosofía. Leída a partir de Quignard, la frase de Foucault significa que el pensamiento retorna al movimiento mismo del retornar de la indigencia; significa que comienza a comenzar, y que en tanto que comienzo, suelta la prenda para 
hacer de toda obra suya la repetición de una pérdida "más fuerte que lo que ella aporta al mundo". En tal sentido, pensamiento sin obra.

El tiempo fuera de sus goznes, la línea recta del tiempo descentrado, fuera de quicio, el tiempo de la re-novación de lo que comienza, es para Quignard el puro salir que avanza en línea directa, tan directa, tan recta, tan rectilínea, como la huida misma. "No es posible ninguna suspensión de ese impulso una vez que el cuerpo se ha entregado a él, propulsado por la estrechez del lugar de origen que lo expulsa". Es el movimiento catastrófico del mismo nacimiento. Movimiento de salida: "en ese vómito, en ese extraño naufragio, el nacimiento solo es comparable a la muerte" (2017 106). Según Quignard, la línea del tiempo como huida es el éxtasis del pensar como escritura, y es el éxtasis mismo del aparecer de lo que nace al mundo, el éxtasis, "el no estar ahí del sí mismo", como el lugar que "tiene lugar" en el arte (2017 110). Pues no solo el nacimiento es danza, también la danza (y, por tanto, el arte) es nacimiento. La escena nocturna del nacimiento que "tiene lugar" en el arte de la danza como soltura de cuerpo; como indigencia repetida y como éxtasis.

\section{6.}

Si para Deleuze, al menos en Diferencia y Repetición, el elemento mínimo de lo viviente es el hábito, y si este es un devenir variable con el mundo, una modificación en la que está implicada un singular modo de habitar o de tener, para Quignard lo que vela en cada hábito es el extremo abismal de lo naciente y de la creación. Llegamos al mundo, según Quignard, como náufragos arrojados sobre la orilla de sombra entre dos abismos: el nacimiento y la muerte. No vemos, no asistimos a la escena de nuestro nacimiento y no vemos, no asistimos a la escena de nuestra muerte. La catástrofe es lo que está en nuestro origen. La consecuencia es que antes de la contemplación plotiniana, antes del devenir cósmico o mixtura estoica, supuestos en el hábito deleuzeano, está el desgarro y el ahogo, la apnea que implica la ausencia de lugar, el vacío primigenio del que sale al mundo sin encontrarse aún en él. "El lugar del nacimiento -escribe Quignard- no es todavía un lugar. El lugar del nacimiento es un tiempo" (2017 109). Es el tiempo del intermundo, del punto de vacilación entre la vida nonata y la vida natal: "punto de nacimiento, de descoordinación, de trauma, de espanto, de trance, de ek-stasis, de desapego" (2017 109).

Parto, en nuestra lengua, tiene el doble sentido de nacimiento y de partida, es el acto de parir y el abandono de un lugar. Parir, par(t)ir. Dejar al cuerpo que te deja, que se desapega y que en el desapego se vuelve cuerpo perdido, abandonado a la incontinencia, al des-contento de una separación originaria y desorientadora. Kata-Strophé, nos dice Quignard, es "voltear hacia abajo", es el gesto danzante del 
movimiento descendente que está en nuestro origen, en nuestro centro. Es la torsión del cuerpo expulsado del primer mundo a la tierra: la muda emotiva del cuerpo-contenido al cuerpo indigente. La catástrofe nombra, ante todo, la ausencia de lugar, la caída fuera del cuerpo en el que éramos y que ya no somos. La catástrofe nombra al cuerpo-en-falta-de-cuerpo, al cuerpo para siempre alienado. ¿Dónde estamos cuando nacemos? En la indigencia, en la desorientación, en el desamparo. Ni interior ni exterior, el espacio del nacimiento, nos dice Quignard, es un punto enigmático, una línea oscura no situable ni delimitable, un puro punto de encrucijada que palpita entre la vida y la muerte. "Existe -escribe Quignard- un punto de apnea que no ek-siste sino en el movimiento de nacer. Punto de apnea que desgarra los pulmones, invadiendo con aire a aquel que se sofoca fuera del agua de donde surge: invadiendo con una nueva vía aérea, psíquica, insuflada, a aquel que muere a la antigua vida" (2017 177).

¿Cabe pensar ese punto de encrucijada que palpita entre la vida y la muerte como la sístole y diástole del hábito, de la vida contemplativa? ¿No es la apnea, por el contrario, la suspensión del ritmo, y esta suspensión la tensión misma de la danza natal? ¿No es la vida cadente, una vida que en la suspensión del ahogo cae y deja caer los modos, que en la impostura de la emoción perinatal hace saltar los hábitos "como un muerto salta fuera de su tumba"? Esa inquietud de sí es la danza, según Quignard. Por un lado, la vida no es más que en el modo de sus hábitos. Por otro lado, no obstante, por ser todo hábito algo adquirido hay una disyunción irreducible entre vida y hábito. La vida naciente se sitúa precisamente en el hiato de esa disyunción. En el punto de tensión, de suspenso entre los dos. “¿Qué es nacer?”, pregunta Quignard. A lo que responde: “Es surgir cayendo”. A lo que a su vez vuelve a preguntar: “¿Qué es surgir cayendo?”. Y responde: “Es surgir fuera de la noche". Es ser en el ek-stasis de la ex-pulsio, de la e-motio (2017 60 y 86). A esta danza de tinieblas que procede de la noche, que no está en la luz, sino que la acompaña como eso que la tienta, es lo que en latín -según Quignardnombra ex-frieda. Ausencia o salida de la paz. Surgimiento, deslumbramiento, ahogamiento pertenecen a "ese aire de espantada natal que se ve en los rostros que todavía no son rostros" (2017 87).

\section{7.}

Al final de su libro Las palabras y las cosas Michel Foucault escribe que "el hombre es una invención cuya fecha reciente muestra con toda facilidad la arqueología de nuestro pensamiento. Y quizá también su próximo fin”. De manera que si esas disposiciones que lo componen desaparecieran tal como aparecieron un día, "entonces podría apostarse a que el hombre se borraría, como en los límites del mar un rostro de arena" (398). 
Sin embargo, podríamos decir que esa borradura del rostro humano es lo que no acaba de terminar precisamente porque no termina de comenzar. Pues es la danza natal de la que venimos y que no es sino, como dice Bataille, la noche del hombre que espanta. Un viejo texto del aún joven Hegel lo dice a su modo:

El hombre es esta noche, esta nada vacía, que en su simplicidad lo envuelve todo, una riqueza de imágenes, de representaciones sin trama [...]. Lo que aquí existe es la noche, el interior de la naturaleza, el puro sí mismo, cerrada noche de fantasmagorías: aquí surge de repente una cabeza ensangrentada, allí otra figura blanca, y se esfuman nuevamente. Si uno mira al hombre a los ojos puede uno ver esa noche, ver al interior de una noche que se torna espantosa: a uno le cuelga delante la noche del mundo (154).

Según esto no podemos decretar la fecha de muerte del hombre, precisamente porque su fin es uno con su aparición, y porque esta aparición (monstruosa) es la imposibilidad de la arqueología, la arqueología imposible del hombre. Su nacimiento es precisamente la imposibilidad de un más allá de él, porque es lo anterior más fuerte que su pasado narrable, lo desemejante que desafía toda tematización y fijación en el tiempo; el "dejo" que deja lo anterior y que borra la línea divisoria entre un antes y un después. Su venida al mundo es lo anterior nocturno insuperable que vela en cada comienzo, como el salto del que venimos y que espanta, que saca del estado de paz, de reconocimiento. La aparición del hombre, la sombra de la imagen faltante que dobla cada manera, cada ser modal del mundo devenido, es "el fondo de desigualdad" sobre el que cada uno habita el mundo sin que sus hábitos den nunca en lo justo. El hábito es la regla nunca en regla del habitar del hombre.

\section{Bibliografía}

Arendt, Hannah. La condición humana. Buenos Aires-Barcelona-México: Paidós, 2005.

Arendt, Hannah. Los orígenes del totalitarismo. Madrid: Alianza Editorial, 2007.

Arendt, Hannah. La vida del espíritu. Buenos Aires-México: Paidós, 2010.

Bataille, Georges. La felicidad, el erotismo y la literatura. Ensayos 1944-1961. Buenos Aires: Adriana Hidalgo, 2001.

Deleuze, Gilles. Diferencia y Repetición. Madrid: Júcar, 1988.

Deleuze, Gilles \& Guattari, Felix. ¿Qué es la filosofía? Barcelona: Anagrama, 1994.

Deleuze, Gilles. Francis Bacon. Lógica de la sensación. Madrid: Arena Libros, 2009.

Didi-Huberman, Georges. El Bailaor de soledades. Valencia: Pre-Textos, 2008.

Foucault, Michel. Las palabras y las cosas. Una arqueología de las ciencias humanas. México: Siglo XXI, 2010. 
Hegel, Georg Wilhelm Friedrich. Filosofía real. México: Fondo de Cultura Económica, 2008.

Nancy, Jean-Luc. La experiencia de la libertad. Barcelona-Buenos Aires-México: Paidós, 1996.

Quignard, Pascal. Sur le Jadis. Paris: Gallimard, 2002.

Quignard, Pascal. “Le passé et la jadis”. Donner à penser, ed. Centre Roland Barthes. Paris: Éditions du Seuil, 2005.

Quignard, Pascal. Sur l'image qui manque à nos jours. Paris: Arlèa, 2014.

Quignard, Pascal. El origen de la danza. Buenos Aires: Interzona, 2017.

Sauvagnargues, Anne. Deleuze. Del animal al arte. Buenos Aires-Madrid: Amorrortu, 2006. 